\title{
Algunos criterios para la comprensión de los extractos de entrevistas televisivas ${ }^{1}$
}

\section{Some criteria for understanding television interview extracts}

\section{Jacques Siracusa}

Universidad Paris VIII, Saint-Denis

Jacques.siracusa@gmail.com

\section{Resumen}

El artículo trata el modo de producción y disposición de los extractos de entrevistas televisivas, proponiendo que éstas no informan sobre la intención comunicativa de los entrevistados sino que corresponden a estrategias discursivas de los propios medios de comunicación, que se configuran, antes que en el discurso mismo, en las condiciones materiales en las que se desarrolla el trabajo periodístico.

Palabras clave: Sociología del periodismo, televisión, discurso mediático.

\section{Abstract}

The paper deals with the way of production and extracts disposal from television interviews, suggesting that they do not report about the interviewed's communicative intention, but they correspond to discursive strategies of the media strategies, which are set up, rather than in the discourse itself, in the material conditions in which journalists work develops.

Keywords: Sociology of journalism, television, media discourse.

\section{Introducción}

Los periodistas televisivos utilizan de variadas maneras los extractos de entrevistas en sus reportajes. Sin embargo, tanto para el teleespectador o para el especialista del análisis de contenidos, estos documentos se parecen y les es difícil imaginar la variedad de usos o las distinciones que eran pertinentes en el momento de la realización o producción del tema. En este artículo, voy a abordar el caso, muy frecuente, en el cual los periodistas quieren decirnos, a 
través de documentos grabados, que ciertos personajes están estableciendo ciertas posiciones frentea un fenómeno dado. Para ello procederéen dos etapas.Enla primera deellas presentaréun conjunto, simplificado para efectos de este texto, de las condiciones que gobiernan la actividad periodística, de manera a mostrar algunas de sus conexiones con dos categorías de imágenes manipuladas. De esta manera, describiré algunas regularidades observables en la repartición de las tareas y las etapas de fabricación. Luego, en la segunda, trataré de un problema de orden lógico que me parece se desprende del análisis precedente. Esto es, ¿̇cuándo un reportero nos presenta un extracto de entrevista, cómo este último, los telespectadores y los analistas llegan a suponer que se trata de lo que quería decir el entrevistado? Una declaración presentada en un reportaje puede ser creída como verificable pero, es preciso agregar verificable en función de un marco conceptual dado. Según las circunstancias, el marco al cual se refiere la declaración transmitida es más o menos concordante con aquel que determinaba el sentido inicial de esta declaración. Me parece que la naturaleza de esta relación depende en parte de las condiciones que gobiernan la actividad profesional y las maneras de hacer de los periodistas, es decir depende de elementos imperceptibles en el material difundido.

Este artículo busca esclarecer de manera más analítica ciertos elementos presentados previamente de forma más descriptiva en el marco de una sociología del trabajo de los reporteros y desde un enfoque de tipo interaccionista o etnometodológico ${ }^{2}$. Para ello, estudié el periodismo televisivo de actualidad de fines de los años 90 en Francia, es decir los noticieros de tres grandes cadenas nacionales (TF1, France 2, France 3) y una estación regional de France 3. En el curso de este estudio realicé observaciones sobre un centenar de jornadas plenas, analicé archivos televisivos de los años 50 y 60, realicé una cincuentena de entrevistas y elaboré estadísticas sobre las carreras profesionales y sobre el contenido de los noticieros televisivos ${ }^{3}$.

El enfoque etnográfico conduce de manera casi natural a concebir los enunciados mediáticos como golpes en un juego colectivo. Entonces, no se trata de analizar estos golpes a partir de distinciones que no hacen o no necesitan hacer los periodistas mismos. Se trata de estudiar la aplicación de las imágenes y ver como estas funcionan en un contexto organizado, es decir pesquisar los criterios compartidos que permiten justificar ciertos tratamientos ${ }^{4}$. Dicho de otra forma, el análisis de contenido puede utilizar este enfoque para evitar dos tipos de confusiones: por una parte, crear distinciones superfluas, ahí donde no existen criterios

2. Mis preguntas en términos de sociología de las profesiones se inspiran de las investigaciones de la tradición de Chicago y de aquellas que derivadas del análisis de la evolución del trabajo, retoman algunas de las ideas de Abbott (1988).

3. Para ver descripciones sociológicas detalladas, ver Siracusa (2001). El presente artículo es un seguimiento más análitico de Siracusa (2004).

4. Yo no propondré una teoría del sentido o de la referencia, sino más bien indicaciones de respuestas, empíricamente fundadas, a preguntas como las siguientes: ¿Cuáles son las conexiones entre el documento audiovisual y la realidad? ¿Qué quieren decir estos enunciados? ¿Qué rol tiene, en el medio periodístico, la práctica que consiste en imbricarlas de determinada manera? 
compartidos colectivamente y donde la indeterminación es inherente al tratamiento. Por la otra, descuidar distinciones que reposan justamente sobre estos criterios. Algunas de estas confusiones son, de hecho, difícilmente eludibles para el teleespectador 5 .

\section{I}

Un telediario reúne diversas categorías de trabajadores según un orden jerárquico relativamente claro.La fabricación corresponde generalmente a una serie de etapas que se suceden respetando los niveles de responsabilidad y que cumplen funciones especializadas. En efecto, la jerarquía de los puestos de trabajo se encuentra estrechamente vinculada a los grados de control sobre la arquitectura del telediario y sobre el contenido de los reportajes. Dicho de manera brutal, los periodistas de más alto rango son también aquellos que se encuentran más alejados del terreno y de la manipulación de las imágenes. Sin embargo, estos son también quienes están más informados sobre los contenidos en un momento dado de la literatura profesional (diarios, dossiers de prensa, revistas, e, magazines, cables de agencias noticiosas y bancos de imágenes). El director define la "línea editorial" del telediario (especialmente sus prioridades temáticas), el redactor en jefe (por lo general a partir de esa literatura) selecciona los temas y, junto a su equipo define el "ángulo" (el enfoque a respetar). El redactor debe entonces realizar un reportaje cuyo marco y cuyos participantes se encuentran ya identificados (ello implica que debe a menudo volver a la literatura para obtener más detalles). El redactor hace contacto con las personas a entrevistar (autorizando eventualmente el rodaje), sale de la redacción para recolectar imágenes con un camarógrafo ${ }^{6}$ a quien deja en el terreno, volviendo a la redacción para escribir un comentario y pedir al montajista un cierto agenciamiento de los pedazos de imagen. Así, en algunas horas, el trabajo puede estar cerrado.

Las condiciones relativas a la división del trabajo y a la construcción del tema están ligadas a las diferencias en la naturaleza del material grabado. Las imágenes, el "audio" (término periodístico), son extractos de entrevistas (de personas que declaran algo frente a la cámara); otras imágenes, que yo llamo "imágenes mudas", tienen un sonido pero no contienen entrevistas (sus contenido el variado, a menudo es un plano fijo o un panorámico e inusualmente una secuencia). El camarógrafo es relativamente autónomo en la toma de imágenes mudas. Sin embargo, este último no participa de su localización ni de su montaje. El redactor (entrevistador) es, por su parte, el principal responsable del audio que ha preparado y que mostrará. Finalmente, el montajista (un técnico) quien está ausente de todas las operaciones anteriores, tiene a menudo un margen de maniobra más amplio en el agenciamiento de las imágenes mudas y depende - en general- de las consignas del redactor acerca del audio.

5. Me inspiré en las reflexiones de Wittgenstein (1961) y en sus comentarios a propósito del lenguaje común. 6. Camarógrafo es aquí utilizado como sinónimo de Periodista reportero de imágenes (PRI) como traducción de Journaliste reporter d'images (JRI). (N. del T.) 
Algunas veces, los documentos provienen del exterior, es decir son comprados o provienen de un banco de imagenes. En estos casos, la repartición en el momento del montaje es análoga y el audio está a cargo de quien escribe el comentario.

En último lugar, habría que agregar una precisión para dar cuenta de la existencia de un funcionamiento, en algunos casos inverso. En efecto, como se desprende de la breve presentación anterior, si bien las imágenes son necesarias para la realización de un reportaje, su contenido tendría, por el contrario, poca importancia en cuanto al orden de las operaciones. Sería, entonces, poco factible que un reportero pudiese poner en entredicho la orden de sus superiores (cambio de enfoque) basándose en el material grabado (observación en el terreno). En los hechos, menos el tema es juzgado como importante o urgente por las jefaturas, menos rígida resulta su orientación y dependencia de la literatura diaria. Así, un tema "ameno" (que usualmente trata de espectáculos o de folclore), algunas veces una semblanza, un dossier o una investigación pueden haber sido realizados según principios jerárquicos invertidos: definición a posteriori del enfoque u otorgar una prioridad a las imágenes (sobretodo mudas) y a los encargados de su manipulación ${ }^{7}$. Pero, es difícil conocer el orden de las operaciones a partir del reportaje difundido, puesto que los trastornos del orden normal tocan sobretodo los temas presentados al final del telediario.

Entre estos dos modos de funcionamiento, el más frecuente desde el punto de vista de la observación es el primero de los antes expuestos. Este es también donde el enfoque depende menos de las vicisitudes del terreno o del saber hacer específico de los realizadores. La existencia de un conjunto de prácticas relativamente estables y ya adquiridas por los periodistas permite una ejecución rápida, previsible y controlable de las operaciones a emprender. Cada uno de los actores involucrados en el proceso (especialmente el jefe) puede verificar si la aplicación de una consigna por otro actor, responde a lo que colectivamente se ha juzgado correcto. Responder correctamente a los pedidos se traduce en la manifestación de ciertos comportamientos observables en bambalinas o en presentar ciertas cosas de una cierta manera en el reportaje difundido. Contrariamente a los “sabios", especialmente en los medios literarios, los periodistas trabajan en empresas comerciales, en el seno de una jerarquía profesional y bajo la amenaza constante de procesos judiciales de parte de las personas o grupos que se sienten maltratados en los reportajes. Contradecir a un superior, ejecutando mal los pedidos) es arriesgar une pérdida de las audiencias, la reputación personal o del telediario (al realizar un tema que sea juzgado como inadecuado o trucado), obstaculizar el trabajo de los colegas (impidiéndoles el ejercicio de su trabajo en buenas condiciones) o exponerse a demandas judiciales (a menudo

7. Los especialistas de las imágenes son los PRI (periodistas reporteros de imágenes) y los montajistas. Algunos indicios observables de esta jerarquía invertida son la mayor intensidad de la participación de los PRI y de los montajistas en la construcción del tema, el rol del comentario en el montaje, la importancia cordada a las cualidades estéticas de las imágenes y de la narración o el desinterés relativo de las jefaturas respecto del contenido informativo del reportaje. 
por difamación) son los resultados de aplicaciones incorrectas de las reglas de trabajo.

El control típico de los jefes reposa sobre criterios utilizables sin necesidad de salir de las oficinas de la cadena televisiva: la producción de los colegas es el principal punto de referencia para evaluar la información. Consideremos, por ejemplo, el caso de un tema calificado de importante por el redactor en jefe. ¿Cómo aprecia este último la justeza del trabajo de su equipo? El redactor en jefe conoce en términos generales las acciones que deben llevar a cabo sus subordinados y el marco conceptual en el cual efectuarán sus investigaciones. El redactor en jefe no anticipa el contenido del reportaje, pero vislumbre a que debe parecerse para construir su noticiero. Al suponer que sus periodistas tienen experiencia, no tiene que controlar la puesta en obra de cada técnica (localización, grabación y montaje). Como antiguo reportero, ha aprendido lo que la aplicación tradicional de cada una de estas técnicas puede ofrecer y en que contextos pueden ser aplicadas. El verificará, en el momento de la difusión, si el enfoque ( el marco lógico) es el definido al inicio de la producción y si la edición de las imágenes es la correcta ${ }^{8}$. El comparará lo que esperaba en vistas de las lecturas iniciales, de las nuevas informaciones recibidas, de lo que la competencia ha hecho en relación al mismo evento. Dicho de otra manera no verificará directamente en el terreno lo que juzga importante y ciertos aspectos del contenido le serán indiferentes ${ }^{9}$. Este tipo de control puede parecer circular (autorreferencial), pero su eficacia reposa sobre la inmensa cantidad de informaciones recibidas de parte de los colegas (o de fuentes institucionales), su frecuente renovación y los criterios compartidos en el seno de la comunidad profesional, para juzgar la importancia de ciertos fenómenos, de la manera precisa de abordarlos y de la credibilidad de las fuentes.

Una huella del uso de estos criterios puede resultar útil para el análisis de contenidos en cuanto a la definición de la importancia de un tema o respecto de su marco lógico (enfoque). En efecto, suele suceder que un reportero esté encargado de la realización de varias versiones de una noticia importante (para los noticieros de mediodía, de tarde, de noche o para el del día siguiente). Por lo general, este profesional realizará una serie de reportajes a partir del mismo material original (sin investigación adicional). Estos reportajes son equivalentes desde el punto de vista de la información, pero distintos en relación a algunos de sus elementos. ¿Qué es lo que varía? ¿Qué es lo que se mantiene sin cambios? Ciertos matices se relacionan, quizás, con la duración (que depende sobretodo del espacio disponible en el telediario); con la "simplicidad" del argumento (el noticiero de las 13 horas es a menudo considerado más popular que los otros y, por lo tanto, se estima necesario "hacerlo más simple") o se reflejan en la elección y en

8. Entiendo por el "juicio sobre una correcta edición de las imágenes", la apreciación del trabajo según un conjunto de convenciones de orden estético y moral respecto de las maneras de presentar un producto "limpio", con tacto y donde se valoriza la imagen pública de la profesión. He desarrollado esta idea en otro texto.

9. Si el tema se encuentra ausente de la literatura y no ha sido tratado por la competencia, se entiende porqué señalé más arriba que las jefaturas se desinteresan a manudo del contenido informativo: estas no tienen a su disposición las referencias de lo que ha sido producido por la comunidad profesional. 
el agenciamiento de las imágenes. Sin embargo, algunos elementos tendrán la misma función y querrán decir lo mismo en cada una de las versiones: sonidos, imágenes mudas y palabras en los comentarios. Identificar lo que se mantiene estable permite establecer el marco lógico y particularmente las informaciones que se juzgan confiables o que provienen de la "literatura" y sobre las cuales este marco reposa. ${ }^{10}$ En revancha, un tema menos "importante" (desarchivado, divertido, que "tapa un hoyo", etc.) tiene menos versiones y es menos difundido y su enfoque tiene más o menos relación con las otras informaciones tratadas por los colegas (este tema puede incluso haber sido construido según una planificación invertida de las tareas) ${ }^{11}$.

La información que se juzga importante y que está controlada por la jerarquía, es sobretodo aquella que se expresa con sonido y con comentarios. La posibilidad de obtenerla es, de hecho, un criterio a menudo decisivo para la realización de un reportaje y para la elección del enfoque. En general, cuando un equipo se desplaza fuera de la redacción, es para entrevistar a una persona ${ }^{12}$. Como lo decía brutalmente un responsable: "si no tenemos sonido, lo dejamos caer". El periodista puede, algunas veces, dejar que el público crea que ha aplicado las normas clásicas, cuando sólo ha reutilizado sonidos realizados por otros o reciclado antiguos reportajes guardados en la videoteca. En todo caso, la energía invertida por el redactor en la investigación o en la entrevista de un interlocutor vinculado al tema y que además de creíble esté dispuesto a aceptar ser grabado es considerable en relación al esfuerzo consagrado a otras tareas. En los hechos, los especialistas de la comunicación se han adaptado a ello y tienen como una de sus funciones generar reportajes al otorgar entrevistas donde intentan hacer funcionar este criterio ${ }^{13}$.

Analizar un reportaje es, entonces, analizar un discurso construido a partir de declaraciones. La importancia del audio se decide antes de su grabación y, por lo general, sobre la base de documentos escritos. No obstante, la norma profesional que consiste en presentar sonidos,

10. Esta sintaxis se inscribe a manudo en un género tradicional, estereotipado : la oposición del usuario respecto de la administración (David contra Goliat), la que existe entre los partidos políticos o entre los ciudadanos (la "micro vereda") respecto de una "fenómeno de sociedad", el "retrato de artista", la "necrología", etc.

11. Desde este punto de vista, los temas que hacen la autopromoción de la cadena televisiva (que alaban los meritos de un programa) tienen un estatus ambiguo. En efecto, si bien tienen una escasa relación con la literatura, son juzgados a partir de razones comerciales (o que dicen relación con los derechos televisivos adquiridos por la estación o la cadena).

12. Una noticia "breve", una "píldora”, un "guiño" o bien una síntesis de dossiers (lo que los periodistas consideran preferible "evitar" porque resulta "indigesto para el público") se montan rápidamente a partir de imágenes exteriores o de gráficos y no necesitan equipos de filmación. De hecho no he observado que periodistas se desplacen con un PRI (camarógrafo) sino es para entrevistar a alguien.

13. La posibilidad de filmar "imágenes bellas" que simbolicen la acción de los propagandistas es también un criterio periodístico explotado por los promotores comunicacionales, pero desde el punto de vista de la definición del enfoque, me parece un factor secundario respecto del primero: en este caso, se trata para los promotores de aprovechar el funcionamiento inverso descrito más arriba donde, algunas veces, las imágenes mudas se tornan centrales y directivas. 
en pasar tiempo tratando de obtenerlos y estructurando el tema en función de estos, genera algunas confusiones: todo lo que tiene forma de sonidos en el reportaje no ha sido tratado de la misma manera por los periodistas y, se puede afirmar, que no tiene el mismo estatus lógico.

\section{II}

Ya he expuesto lo que acontece en el segundo plano, ahora me interesaré en el problema de la correspondencia entre el significado de la declaración en el momento en el cual esta se hace y su significado en el momento en el que esta se difunde. ¿Qué garantía podemos tener respecto de lo que una persona (entrevistado o entrevistador) ha comprendido en un momento dado será utilizado correctamente por otra persona (redactor o montajista) en el futuro? Desde un cierto punto de vista, los elementos grabados reproducen de manera fiel la realidad, pero su modo de grabación es variable y, por consiguiente, la realidad en cuestión es ambigua. Las combinaciones posibles en el montaje son múltiples. Pero la filmación y el montaje me parecen seguir ciertas reglas cuyos modos de aplicación están más o menos instituidos, aunque sea de difícil comprensión a partir del reportaje difundido.

Un medio para precisar el cambio eventual de contexto (sentido) es comprender cómo una declaración se proyecta desde un espacio hacia otro y considerando los diferentes modos de proyección. El caso de un audio de un "portavoz oficial, en conferencia de prensa, abordando un fenómeno ya tratado por los colegas” me parece juega aquí el rol de un modelo en la aplicación de las técnicas de proyección. La organización del trabajo está particularmente adaptada a su tratamiento y los criterios colectivos son utilizables para verificar la justeza de este audio. En otros casos, por el contrario, el audio se realiza sin apoyarse en estos criterios. Si sistema de referencia de la declaración cambia o no, no existen medios compartidos colectivamente por los periodistas que permiten reconocer estos cambios. Entonces, tampoco existen garantías para el telespectador.

Los periodistas y montajistas buscan que el telespectador pueda hacer una interpretación que no resulte problemática. Esto se puede verificar o comprender al observarlos o al preguntarles por las razones de sus acciones. El reportaje se supone reposa sobre documentos "auténticos" y, desde su inicio, sobre el anuncio de su contenido. Frente la pregunta sobre qué hablan las imágenes. La respuesta buscada en el telespectador refiere a lo que se percibe de manera inmediata. Si se ve al "portavoz R diciendo, en una conferencia de prensa, la frase P a propósito de la posición oficial de su institución en cuanto al problema Q", se nos conduce a comprender estas imágenes de "R dice P" según el enfoque en cuestión, es decir el marco conceptual donde el relato estructura al tema.

Sin embargo, qué puede contestar el telespectador frente a la pregunta siguiente: ¿cómo se debe proceder para llegar a decidir si el extracto "R dice P" es verdadero o falso? Es decir, cuál es el método para verificarlo? (No estoy hablando aquí de la veracidad de P, puesto que el 
telespectador es conducido, a partir del relato, muchas veces a dudar de ello ${ }^{14}$ ). El telespectador, al desconocer esta forma de comunicación, es llevado a pensar que es verdad que "R dice P" puesto que tiene la prueba visible (y tiene confianza en los periodistas) o bien es imagina acciones misteriosas o deshonestas (trucajes). El periodista podría establecer a que hecho verificable corresponde el pedazo de imagen en cuestión. El portavoz ha dicho efectivamente esta frase ante una asamblea de periodistas o él u otros miembros de su institución han repetido en otra parte una frase equivalente a varios colegas: existen entonces pruebas, informadas por la comunidad de pares, que "R dijo P". Dicho de otra forma, el telespectador que lee distintos diarios y que mira distintos telediarios podría utilizar el mismo criterio (o invocar una maquinación).

Pero, ¿"R dice P” significa, en el reportaje, lo que R quería decir? Y, ¿el marco lógico del reportaje montado es análogo a aquel desde donde se extrajo la expresión de R? Este es el problema de las significaciones compartidas. El telespectador, a menos que tenga un acceso a R o un conocimiento directo del fenómeno $\mathrm{Q}$, no tiene medios para responder a ello a partir de un solo reportaje. El periodista podría justificarse describiendo, a partir de sus fuentes tradicionales o de su conocimientos personal de $\mathrm{Q}$ las diversas posiciones pensables (el sistema de referencias), luego al mostrar que $\mathrm{R}$ se ha inscrito por si mismo en este marco y que $\mathrm{P}$ es presentado según el enfoque en cuestión, es un buen resumen. El telespectador que consulte distintos diarios podría concluir, a partir de un consenso observable, que la significación es efectivamente compartida entre R y los periodistas o bien que se trata sólo del resultado de una matriz de lectura común en la profesión y que aquí se pone en operación. De manera más justa. podría pensar que esta significación compartida puede también reposar sobre el conocimiento de R sobre los saberes periodísticos, es decir sobre una suerte de acuerdo entre las partes sobre lo que constituye lo esencial del mensaje.

El entrevistador es, de mayor o menor forma, guiado en su investigación por un marco en el cual las informaciones adquieren sentido. La correspondencia entre este sistema de referencia y aquel que determina las palabras de su interlocutor está más o menos asegurada al inicio. Esta correspondencia depende sobretodo de los medios de conocimiento de los que dispone el periodista (quien, recordemos, tiene poco tiempo y efectúa generalmente una investigación previa literaria y telefónica para su marco de referencia). Esta correspondencia se vincula entonces a los recursos que tiene el interlocutor para darse a conocer antes de la grabación misma. A menudo, cuando se graba, el redactor intenta conciliar lo que se le ha pedido de parte de la jefatura con lo que juzga es la significación de las palabras del entrevistado. Pero, la marcación es, a veces, demasiado sucinta y la distancia entre los dos puntos de vista

14. No insistiré aquí sobre la importancia que adquieren las declaraciones de intención o las restituciones verbales de comportamientos en las informaciones televisadas (e incluso escritas o radiofónicas). Los reporteros de televisión, ya lo habremos comprendido, consagran pocas energías a investigar y confrontar cada declaración a la realidad. Sobre este punto, y a propósito de los trabajos sociológicos que han tratado de ello, ver I. Deutscher, F. Pestello, H. Pestello (1993). 
es demasiado grande para ser realizable. El redactor impone entonces su cuestionamiento, más aún, cuando el interlocutor cuenta con menos recursos para imponer su discurso o su decoración (o proponer uno que convenga a las partes).

Un principio de variación observable en la aplicación de la técnica de la entrevista reposa sobre el tipo de interlocutor o sobre la configuración del rodaje: el método de recolección depende de alguna manera de lo que es recolectado. La situación del portavoz en conferencia de prensa se opone, en términos de control de la situación, a la de un anónimo que acepta la presencia de un equipo en su domicilio. Una declaración oficial es, a menudo, una performance bajo el control del portavoz, tanto desde el punto de vista de la puesta en escena como del contenido del discurso. En general, los reporteros se satisfacen con lo que les es ofrecido (obtener otra cosa es, por lo demás, difícil) y juzgan que esta información es importante o corresponde a lo que esperaban. Esta información se opone, a veces, a otra del mismo tipo, dada en un marco material y conceptual análogo. Por el contrario, en el caso de una anónimo, si el reportero no tiene mucho tiempo para consagrarle (lo que es la situación más frecuente), este último buscará respuestas (correctamente formuladas) a sus propias preguntas, cuyo sentido reenvía a un marco difícilmente imaginable por su interlocutor. El interlocutor se expresará en referencia a un contexto probablemente oscuro para el reportero (al menos en buena parte). Entre estos dos casos extremos, existen numerosas situaciones de entrevista que son analizables como casos intermedios.

El caso tipo de la entrevista descontextualizada ("recuadrada" o "recentrada”, según los periodistas) es aquella realizada para ilustrar una información oficial (recolectada en la oficina): el audio del anónimo sirve entonces a fortalecerla o a criticarla. En fin, el caso limite de este tipo de cambio de sistema de referencia es la realización de ciertas "micro-veredas" donde los transeúntes son entrevistados por algunos segundos: poco importa lo que el reportero recolecte, este encontraré lo que busca ${ }^{15}$.

Sin embargo, la significación de un documento (imagen o sonido) está determinada por el periodista o el montajista en función de lo que estos quieren decir en el momento del montaje. El tema montado no es ni un muestreo representativo del material grabado (la relación entre lo montado y lo grabado es, a menudo, del orden de 1/20) ni una síntesis obligada de las operaciones anteriores $^{16}$. ¿Qué es lo que, en esta situación de trabajo, limita la multitud de

15. Incluso en la situación más favorable para el anónimo (el tema se juzga como poco importantes y poco urgente, reposa sobre "bella imágenes" o un "retrato" y su enfoque está vagamente definido desde el inicio), los reporteros intentan imponer su puesta en escena y sus preguntas. Esto facilita el trabajo (en el momento y luego, en el montaje). Por ejemplo, yo había observado el caso de un artesano que aceptó, respondiendo a las necesidades del rodaje, exponer su técnica de manera más telegénica. Después de todo, los reporteros consideran, en general, que ellos son quienes saben cómo se hace y lo que es importante y comprensible para el público.

16. Cuando los reporteros dicen que han realizado un "premontaje", esto quiere decir que sólo han grabado aquello que les sirve y según una puesta en forma correcta. Dicho de manera brutal, entre más exigente es la primera proyección, menos lo son las que le siguen. 
composiciones factibles? Para muchos reportajes, especialmente aquellos cuyo enfoque se define antes del montaje, el observador podría imaginar que existe una rejilla a través de la cual el redactor interpreta las imágenes. Sin embargo, me parece más pertinente sustentar la explicación sobre comportamientos observables.

Una huella visible de esta rejilla, en el momento del montaje, es la lista de dérushage ${ }^{17}$ : una descripción del contenido del material en función de las categorías adaptadas del enfoque tomado ${ }^{18}$. Las imágenes son primero clasificadas. Luego se recortan y se pegan para hacer aparente una estructura ya implícita en la lista eventual de dérushage, pero que no es necesariamente aquella que está al origen del audio (o de las imágenes mudas). Este último aspecto es particularmente evidente cuando un periodista reutiliza imágenes grabadas por otro equipo y que provienen de un viejo tema o de un banco de imágenes y que son agenciadas según otro ángulo. Desde el punto de vista de la división de las tareas, esta reinterpretación es difícil de evitar, sobretodo en lo que concierne a las imágenes mudas: el PRI suele trabajar solo y no participa de la localización ni del montaje.

Otro tipo de huellas de esta rejilla es el conjunto de argumentos verbales que da el redactor respecto de sus elecciones y que intercambia con el montajista o con un superior jerárquico. Si usted le pregunta, frente a sus rushes (el material recolectado), cuál es su criterio para elegir un extracto más que otro, él lo reenviará a su ángulo, a consideraciones técnico-artísticas, de gusto de sentido común y quizás a su conocimiento del oficio. El podría decirle para que sirve tal pedazo de imágenes (su función en el reportaje : ilustrar un argumento, jugar un rol de transición, tapar un hoyo, etc.), que otros pedazos son equivalentes (sinónimos, entonces redundantes) para lo que quiere decir, que un personaje elegido era "divertido" o un plano "simpático", que el montajista le propuso dicha composición, etc.

La aplicación de las técnicas de montaje varían según la importancia del tema (la prioridad del audio o de las imágenes mudas) y el grado de participación del técnico: puede tratarse de ilustrar un comentario ya escrito o, por el contrario, agenciar imágenes (sobre todo mudas) y presentarlas para comentar. A menudo, el tratamiento del audio es central y directivo ${ }^{19}$. Dos ejemplos de reducción típicos son los siguientes: el más frecuente consisten en conservar sólo los trozos de ciertos audio (a menudo los anónimos) que responden a otro audio (a menudo los de los portavoces oficiales) que se consideran importantes porque "pegan" con el enfoque. Otra técnica consiste, a partir de una frase larga del entrevistado, constituida por

17. Le dérushage es la primera etapa del montaje de un programa audiovisual y permite la selección de todos los materiales que serán utilizados en el montaje. (N. del T.)

18. Es notable que esta lista es, en general, realizada visionando las imágenes mudas con velocidad rápida y luego sin sonido y en una velocidad normal de manera a escuchar ciertos tramos de audio.

19. Las imágenes mudas sirven sobre todo para ilustrar palabras y la significación que el reportero les da es aún más dependiente de las palabras que las acompañarán. Una misma imagen muda puede querer describir palabras pronunciadas, evocar ideas que no pueden ser dichas, a veces contradecir un audio e incluso no decir nada más que aquello que dice una conjunción de coordinación como "y" o una puntuación. 
una proposición principal y otras relativas, en extraer una de las relativas que "calcen bien con el tema”.

Algunos audio difundidos adquieren entonces una significación que no es la que les daba el entrevistado. A veces, la mejor explicación de la presencia de un audio es la posibilidad que el periodista veía para ilustrar una posición determinada por el enfoque del tema o el marco conceptual, considerado central, del audio de otra persona.

\section{III}

El análisis de contenido de los reportajes, me parece, levanta entonces problemas porque la veracidad de los documentos (podría decirse, en un sentido positivista) es puesta en un primer plano y que estos documentos "verdaderos" tienen aparentemente la misma forma; mientras que, en cuanto no son tratados de la misma manera, no me parecen demandar el mismo tipo de explicación. Desde el punto de vista de las operaciones efectuadas por el periodista, se puede efectivamente distinguir dos grandes categorías de audio: aquellos presentados en un marco conceptual análogo a aquel que empleaba el entrevistado y los otros. Por análogo estoy entendiendo un marco cual las diversas posiciones consideradas corresponden a aquellas implícitas en el discurso del entrevistado. En ciertas circunstancias, el entrevistado y el entrevistador se entienden rápidamente y este último mantiene esta concordancia y la presenta en un tema de un minuto y treinta segundos de duración.

En el caso del funcionamiento más frecuente, aquel que se adapta a los temas importantes o urgentes, tratados por la mayoría de los colegas y completamente realizados por un equipo del noticiero, el encadenamiento de las etapas donde se elaboran significaciones concordantes y que pueden ser elaboradas y mantenidas colectivamente, es el siguiente: las informaciones a propósito de lo que quiere decir el personaje existen ya en la literatura consultada por los responsables del noticiero; el enfoque se define en función de estas informaciones; las preguntas en el momento de la entrevista o las declaraciones del personaje se inscriben en este marco; el dérushage y la estructura final siguen el mismo sistema de referencia (el tema puede evidentemente presentar posiciones divergentes de la del personaje entrevistado, lo que es a menudo el caso). La organización del trabajo, el saber de los reporteros (y de los montajistas) y el modo típico de control de las jefaturas (podríamos agregar la colaboración del personaje o su capacidad de controlar la grabación) contribuyen a producir, en algunas horas, una cuenta de la posición de esta persona, justificable según criterios profesionales.

Pero, si esta persona o su posición están ausentes de la literatura o son desconocidas por el redactor en jefe, si la persona misma ignora el enfoque del tema o no es conocida por el redactor, entonces la justeza de lo que ella dice en el reportaje no puede demostrarse a partir de los criterios expuestos. El dispositivo colectivo no puede funcionar $y$, aún cuando una persona haya realmente dicho aquello que se escucha y que el audio parece naturalmente inscrito en el enfoque del tema, la composición final del reportaje expresa a veces una situación ficticia para 
el entrevistado. El documento presentado es una suerte de artefacto periodístico: el vínculo (de orden semántico) entre lo que dijo y lo que quería decir la persona visible en pantalla es de alguna manera tan flojo como el vínculo (en términos de interconocimiento) entre el realizador del documento y el entrevistado.

$\mathrm{Al}$ contrario, en el caso raro de un funcionamiento invertido, el enfoque se elabora progresivamente en función del material recolectado y puede algunas veces ajustarse a lo que el personaje quería decir en el momento de la entrevista. Algunos "retratos" o "investigaciones", realizadas con más tiempo y según un modo de colaboración diferente (redactor-PRI y redactor-montajista), contienen audio estandardizados, pero construidos en función de lo que sus interlocutores (a menudo anónimos) consideraron importante. No obstante, si el trabajo de los colegas o de la competencia no tiene relación con el tema, cómo justificar la justeza de estos audios sin depender únicamente de la pericia escondida de estos tres trabajadores? Dicho de otra forma, cómo saber que no se trata, nuevamente, de un artefacto?

Desde el punto de vista del análisis del trabajo de los periodistas, el problema de la justeza de ciertas representaciones resulta de las formas diferenciadas de tratamiento ${ }^{20}$. En efecto, he abordado aquí la noción de representación en diferentes sentidos, aquellos que me parecían corresponder al uso que hacen los periodistas de este término en su trabajo. En general, ellos buscan tratar eventos que juzgan "representativos", es decir que conciernen o interesan a un vasto público. Los periodistas conversan entonces a menudo con "representantes" de organismo oficiales, con portavoces que se suponen defienden ciertas posiciones o resuelven ciertos problemas. Los periodistas pretenden, algunas veces, confrontar estas posiciones oficiales con las de personas que no están "representadas", es decir una categoría de individuos sin portavoz pero relacionados con el fenómeno considerado. Los periodistas juegan entonces un rol de "representantes", en un sentido a la vez social y lógico, constituyendo y luego difundiendo una o más posiciones alternativas a aquellas que emanan de las fuentes oficiales. Cuando elaboran el reportaje, se encargan de estructurar conceptualmente los extractos de entrevista, a menudo guiados por sus referencias más asequibles. Cómo podrían pensar en orientar sus esfuerzos de otra manera en una organización donde las incitaciones de orden colectivo empujan antes que nada al tratamiento rápido de los discursos oficiales?

En fin, desde el punto de vista del análisis de contenidos de los reportajes televisivos, el problema de la representación es, desde mi punto de vista, el de la falsa semejanza entre documentos realizados de maneras diferentes. Pienso haber demostrado que es más que difícil, a partir solamente del producto terminado, imaginar el ambiente intelectual y material, y para los periodistas y, mucho más, diferenciar las distinciones que estos juzgan pertinentes

20. Puede parecer paradojal que el método más sensible a las declaraciones de individuos sin portavoces sea la menos frecuente, la menos retomada por los colegas y, por ello, la menos controlable, mientras que las declaraciones, elaboradas según el método más frecuente y cuyo significado es artificial, sirven a veces de contrapeso político (como la utilización de ciertos resultados de sondeos de opinión). 
en el curso del proceso de fabricación. El telespectador está, en efecto, tentado de considerar el contenido de las imágenes como central y primero. Asimismo, tenderá a pensar que los audios formalmente equivalentes son el resultado de operaciones equivalentes. En los hechos, los periodistas están en un contexto donde, la mayor parte del tiempo, no toman conocimiento de aquello que tratan mediante imágenes y se sirven de estas antes que todo como ilustraciones de lo que quieren decir. Los periodistas las recogen y las aplican guiándose por un marco conceptual más o menos concordante con el del entrevistado.

He tratado aquí de promover un análisis del sentido de las declaraciones difundidas, tomando en cuenta la participación de sus autores en una actividad instituida y formulando esta pregunta central: cómo se elaboran y utilizan estos documentos? He presentado trazos pertinentes del contexto de trabajo y algunos principios de variación en los comportamientos observables. He defendido la idea de que los periodistas, los telespectadores y los especialistas del análisis de contenidos pueden, de manera más o menos justificada, creer que los extractos de entrevistas corresponden a los que los entrevistados querían decir.

\section{Referencias bibliográfícas}

Abbott, A. (1988). The system of professions. An Essay on the Division of Expert Labor. The University of Chicago Press.

Deutscher, I. ; Pestello, F.; Pestello, H. (1993). Sentiments and Acts. New York: Aldine de Gruyter.

Siracusa, J. (2001). Le JT, machine à décrire. Sociologie du travail des reporters à la télévision. Paris-Bruxelles: INA-De Boeck.

—_ (2004). «Eléments pour une sociologie du travail des informations télévisées». Knowledge, Work and Society Vol. $2 \mathrm{~N}^{\circ}$ 3. pp. 57-72.

Wittgenstein, L. (1961). Tractatus logico-philosophicus seguido de Investigations philosophiques. Paris: Gallimard. 